\title{
Comparison of Standardized Dichloromethane with Aqueous Pterodon pubescens Benth. Fruit Extracts on Antinociceptive and Anti-Inflammatory Activity
}

\author{
Rogério Grando, ${ }^{a}$ Vanessa H. Souza, ${ }^{b}$ Karin M. Monteiro, ${ }^{c}$ Ilza M. O. Sousa, ${ }^{a}$ Nubia C \\ A. Queiroz, ${ }^{d}$ João E. Carvalho, ${ }^{b, c, d}$ Humberto M. Spindola ${ }^{d}$ and Mary A. Foglio*,a,b,d \\ ${ }^{a}$ Departamento de Ciências Médicas, Faculdade de Ciências Médicas, \\ Universidade Estadual de Campinas, P.O. Box 611, 13083-970 Campinas-SP, Brazil
}

${ }^{b}$ Departamento de Ciências Fisiológicas, Faculdade de Odontologia de Piracicaba, Universidade Estadual de Campinas, P.O. Box 52, 13414-903 Piracicaba-SP, Brazil

'Departamento de Clínica Médica, Faculdade de Ciências Médicas, Universidade Estadual de Campinas, P.O. Box 611, 13083-970 Campinas-SP, Brazil

${ }^{d}$ Faculdade de Ciências Farmacêuticas (FCF), Universidade Estadual de Campinas, P.O. Box 6029, 13083-859 Campinas-SP, Brazil

\begin{abstract}
Pterodon pubescens Benth., popularly known as "sucupira", is traditionally used as pain healing agent for many inflammatory diseases. The present study evaluated the in vivo antinociceptive and anti-inflammatory properties of sucupira's fruit dicloromethane extract $(\mathrm{Pp})$ compared to the aqueous extract (Ppa) traditionally used in folk medicine. Extracts' chemical characterization was performed by gas chromatography coupled to mass spectra (GC-MS) detection. The standardized extracts were evaluated using antinociceptive and anti-inflammatory experimental models with mice. The results reported herein allowed establishing a relationship between the popular use of Pterodon pubescens fruit for pain relief and the activity of two major compounds isolated from this species which demonstrated antinociceptive activity. The experimental models corroborate activity of aqueous extract antinociceptive and anti-inflammatory activity, with lower potency compared to dichloromethane extract. Nevertheless the resulting data corroborates sucupira's folk use for pain relief.
\end{abstract}

Keywords: Pterodon pubescens Benth., antinociceptive, furanditerpenes, sucupira, biological and pharmacological activities

\section{Introduction}

The study of inflammatory pain has been one of the most rapidly advancing and expanding areas of pain research. The chronic rheumatoid arthritis affects approximately $0.5-1 \%$ of the population, being among the main causes of adult disabilities characterized by spontaneity as well as lowered pain thresholds and increased sensitivity to pressure and temperature. ${ }^{1-5}$ Chronic pain differs from acute pain not only in onset and duration, but more importantly in the underlying mechanisms, poorly responding to the usual drugs for acute pain. In order to improve chronic pain diseases treatment, a clear understanding of what leads to such persistent pain (visceral, inflammatory, and

*e-mail: maryann.foglio@fcf.unicamp.br neuropathic) is required. Therefore testing pharmacological agents in such settings is the best way to explore new drug leads for chronic pain relief. An important source for this purpose is medicinal plants. ${ }^{6}$

Pterodon pubescens' fruit decoction is widely used in Brazilian folk medicine for treatment of several chronic diseases such as rheumatism and arthritis. ${ }^{7,8}$ The pharmacological properties of extracts, fractions and compounds obtained from P. pubescens have been reported for anti-parasitic, antitumor, anti-inflammatory, and antinociceptive activities. ${ }^{7-25}$ However, there is no scientific evidence reported concerning the antinociceptive and anti-inflammatory effectiveness of the aqueous extract or data supporting the ethno pharmacological use. Therefore, herein the differences in chemical profile, in vivo analgesic and anti-inflammatory properties of 
the dichloromethane $P$. pubescens fruit extract (Pp) and aqueous $P$. pubescens fruit extract (Ppa) is reported. The extracts' pharmacological efficiency and chemical profile were determined to support the species use for oral pain treatment. These results are indispensable for the production of effective and standardized herbal extracts aiming the development of herbal medicines. , $^{8,23}$

\section{Experimental}

Pterodon pubescens fruit were previously collected in Minas Gerais State (Ponto Chique City), in September 2011 and identified by Prof Dr Jorge Yoshio Tamashiro from IB-UNICAMP (Department of Botany), who identified the plant species. A voucher specimen was deposited at the University of Campinas (UNICAMP) Herbarium, under number 179740. Access to genetic resources (CGEN) was authorized under process number 010495/2012-6.

Freeze-dried fruit (100 g) were ground prior to use in a Stephen mill (model UM 40) and extracted with dichloromethane by soxhlet extraction system using a 1:3 ratio on mass basis (ground fruit:solvent). Subsequently the extract was concentrated under vacuum (Buchi RE 120) yielding $32 \%$ crude extract. The aqueous extract was produced by extraction with a reflux system using a 1:25 ratio on mass basis (ground fruit: $\mathrm{H}_{2} \mathrm{O}$ ). Extraction was carried out for a period of 1 hour after water started boiling. The solution was cooled to room temperature, concentrated under vacuum (Buchi RE 120) and freeze dried (Virtis ${ }^{\circledR}$, Model 8L) yielding 14\% crude aqueous extract.

The gas chromatography-mass spectrometry (GC-MS) analysis was carried out using a HP-6890/5975 system equipped with a J\&W Scientific DB-5 fused capillary column $(25 \mathrm{~m} \times 0.2 \mathrm{~mm} \times 0.33 \mathrm{~m})$. Temperature program: $60{ }^{\circ} \mathrm{C}\left(5^{\circ} \mathrm{C} \mathrm{min}-1\right)$ to $300{ }^{\circ} \mathrm{C}(10 \mathrm{~min})$, injector $250{ }^{\circ} \mathrm{C}$, detector $300^{\circ} \mathrm{C}$. Helium was used as carrier gas $(0.7$ bars, $1 \mathrm{~mL} \mathrm{~min}^{-1}$ ). The MS were taken at $70 \mathrm{eV}$. Scanning speed was 0.84 scans $\mathrm{s}^{-1}$, from 40 to 550 . Sample volume was $1 \mu$ L. Split: 1:40.

Relative abundance of $6 \alpha, 7 \beta$-dihydroxyvouacapan$17 \beta$-oate methyl ester and isomers $6 \alpha$-hydroxy-7 $\beta$ acetoxy-vouacapan-17 $\beta$-oate methyl ester and $6 \alpha$-acetoxy$7 \beta$-hydroxy-vouacapan-17 $\beta$-oate methyl ester and geranylgeraniol in crude $P$. pubescens extract were measured by area normalization method. The Pp analysis determined $3.7 \%$ of $6 \alpha, 7 \beta$-dihydroxyvouacapan-17 $\beta$-oate methyl ester; $9.0 \%$ of $6 \alpha$-acetoxy-7 $\beta$-hydroxy-vouacapan$17 \beta$-oate methyl ester; $12 \%$ of $6 \alpha, 7 \beta$-dihydroxyvouacapan$17 \beta$-oate methyl ester; and $9.3 \%$ of geranylgeraniol. The Ppa extract analysis determined $11.7 \%$ of $6 \alpha, 7 \beta$ dihydroxyvouacapan-17 $\beta$-oate methyl ester; $7.0 \%$ of
$6 \alpha$-acetoxy-7 $\beta$-hydroxy-vouacapan-17 $\beta$-oate methyl ester; $9.6 \%$ of $6 \alpha, 7 \beta$-dihydroxyvouacapan- $17 \beta$-oate methyl ester; and absence of geranylgeraniol content under analysis conditions employed. Standards were previously isolated from dichloromethane $P$. pubescens fruit crude extract, comparing spectral data to that of authentic samples reported previously. ${ }^{15,22}$

Male Swiss mice and male Wistar rats with 25-35 g and 200-250 g body weight, respectively, were kept at $25 \pm 2{ }^{\circ} \mathrm{C}$ in $12 \mathrm{~h}$ light-dark cycles (light phase started at 7:00 am), maintained (mice: 10 animals per cage; rats: 5 animals per cage) with water and food ad libitum, at least for 7 days prior to assays. Animals were fasted 12 hours prior to oral administration of compounds, in order to avoid possible pharmacokinetic interactions. Separate mice groups were used for each analgesic test and administration route. Animals were used only once in acute experiments. Studies were carried out in accordance with current guidelines for the veterinary care of laboratory animals and were performed under the consent and surveillance of UNICAMP's Institute of Biology Ethics Committee for Animal Research (2367-1). ${ }^{26}$

All drugs and extracts were diluted in $1 \%$ Tween $80^{\circledR}$ vehicle (Sigma-Aldrich, USA) in $0.9 \%$ saline solution ( $\mathrm{NaCl}$ diluted in distilled water). The following substances were used: dexamethasone (Sigma-Aldrich, USA), pentobarbital, (Cristália, Brazil), acetic acid, carrageenan (Sigma-Aldrich, USA), complete Freund adjuvant (SigmaAldrich, USA), and formaldehyde (Chemco, Brazil).

The ambulatory behavior was assessed in an open-field test as previously described. ${ }^{8}$ The apparatus consisted of a plastic box measuring $45 \times 45 \times 20 \mathrm{~cm}$, with the floor divided into 9 equal squares $(15 \times 15 \mathrm{~cm})$. The number of squares crossed with all paws (crossing) was counted in a 3 min session. Mice were 60 min previously treated orally (p.o.) with dichloromethane P. pubescens fruit extract (Pp) and aqueous $P$. pubescens fruit extract (Ppa) (30, 100 and $300 \mathrm{mg} \mathrm{kg}^{-1}$ ), pentobarbital (35 $\mathrm{mg} \mathrm{kg}^{-1}$ ) or vehicle. Results were expressed as mean \pm S.E.M. of 6 animals per group.

The writhing test was carried out as described previously. ${ }^{27,28}$ Groups of mice $(n=6)$ were treated orally (p.o.) with vehicle $\left(10 \mathrm{~mL} \mathrm{~kg}^{-1}\right)$, dichloromethane $P$. pubescens fruit extract $(\mathrm{Pp})$ and aqueous $P$. pubescens fruit extract (Ppa) using three doses 10, 30, and $100 \mathrm{mg} \mathrm{kg}^{-1}$. Writhing was induced by an i.P. injection of $0.8 \%$ acetic acid solution $\left(0.1 \mathrm{~mL} 10 \mathrm{~g}^{-1}\right), 60 \mathrm{~min}$ afterwards. The numbers of writhing (abdominal constrictions) were cumulatively counted over 15 minutes, for nociception evaluation. Data represent the average of the total writhing observed per dose concentration. 
Formalin-induced nociception was measured as previously described. ${ }^{28,29}$ Groups of mice $(\mathrm{n}=6)$ were treated orally (p.o.) with vehicle $\left(10 \mathrm{mg} \mathrm{kg}^{-1}\right)$, dichloromethane $P$. pubescens fruit extract $(\mathrm{Pp})$ and aqueous $P$. pubescens fruit extract (Ppa) using 30, 100, and $300 \mathrm{mg} \mathrm{kg}^{-1}$ doses. For nociception induction, animals received $20 \mu \mathrm{L}$ intraplantar injection of a $2 \%$ formaline solution (formaldehyde in saline solution, $0.9 \% \mathrm{NaCl}$ and distilled water) in the ventral surface of the right hind paw, $60 \mathrm{~min}$ after treatments. Animals were then observed for $30 \mathrm{~min}$, between 0 and $5 \mathrm{~min}$ represented the neurogenic (early) phase, and between 15 and $30 \mathrm{~min}$ represented the inflammatory (late) phase. The time the animals spent licking or biting the injected paw was recorded as indicative of nociception. The reduction of time that treated group spent licking the paw compared to the control group was considered expression of antinociceptive activity.

The procedures used for this study were similar to those described previously by Winter et al. ${ }^{30}$ with some changes in the protocol and data analysis. The animals received $100 \mu \mathrm{L}$ saline (0.9\%) intraplantar injections into the right hind paw containing carrageenan $\left(300 \mu \mathrm{g} \mathrm{paw}^{-1}\right)$. The animals were pretreated p.o. with vehicle (control group) and $\mathrm{Pp}$ and Ppa extracts (30, 100 and $\left.300 \mathrm{mg} \mathrm{kg}^{-1}\right), 60 \mathrm{~min}$ prior to edema induction. The paw edema thickness was measured using a plethysmometer (Ugo Basile, Italy) 2, 4 and $6 \mathrm{~h}$ after edema induction. All of the assessments were performed by the same investigator in order to reduce any potential inter-operator differences.

The procedures used for this study were similar to those described previously by Spindola et al. ${ }^{23}$ with some changes in the protocol and data analysis. Different groups of rats $(n=6)$ were submitted to pressure stimulus (0 to $500 \mathrm{~g}$ ) on the right hind paw using an analgesy-meter (Ugo Basile, Italy) prior to carrageenan injection, in order to determine the basal value. The hyper nociceptive response was considered when animals vocalized or withdrew the paw from the equipment, demonstrating pain. After this first measurement, animals received a carrageenan $(0.1 \mathrm{~mL})$ intraplantar (i.pl.) injection (2.5\% in saline) into the right hind paw surface. After $2.5 \mathrm{~h}$, they were submitted to pressure again, to evaluate whether the hyper nociceptive state was reached ( $40 \%$ decrease). Animals were then treated with vehicle $\left(10 \mathrm{~mL} \mathrm{~kg}^{-1}\right.$, i.p., negative control), Pp and Ppa extracts (30, 100 and $300 \mathrm{mg} \mathrm{kg}^{-1}$, p.o.), with mechanical hyperalgesia measurement evaluated after 2 and $3 \mathrm{~h}$. The value demonstrating mechanical hyperalgesia was obtained after each measurement, and the results were shown as decreased percentage compared to the pressure tolerated in the basal (100\%) value for each group.
The complete Freund's adjuvant (CFA) solution (1 $\mathrm{mg} \mathrm{mL}^{-1}$ of heat killed Mycobacterium tuberculosis in $85 \%$ paraffin oil and $15 \%$ mannide monooleate) was used to produce chronic inflammation and arthritis in rats. The procedures used for this study were similar to those described previously by Omura et al..$^{31}$ with some changes in the protocol and data analysis. The rats received $100 \mu \mathrm{L}$ of CFA intraplantar injection into the right hind paw. The daily oral treatments began 7 days after CFA injection during 14 days (enough to reproduce arthritis), as follows: negative control (saline solution only), positive control (3 mg kg-1 dexamethasone), Pp extract (30, 100 and $300 \mathrm{mg} \mathrm{kg}^{-1}$ ), and Ppa extract (30, 100 and $\left.300 \mathrm{mg} \mathrm{kg}^{-1}\right)$. Two different analyses were performed in order to measure the effectiveness of both extracts against CFA-induced arthritis. The arthritis index was determined by monitoring paw edema (swelling) with a digital plethysmometer (Ugo Basile, Italy) and calculated according to the formula: $\mathrm{AI}(\%)=($ injected paw volume - baseline volume $) \times 100$ baseline volume ${ }^{-1}$. The measurements were made on day 0 (baseline before CFA-injection), and days 7, 14, and 21 after CFA-injection. Results were analyzed comparing treated groups with negative control (saline). Mechanical allodynia was assessed using the dynamic plantar aesthesiometer apparatus (Ugo Basile, mod 37450, Italy) which consisted of an elevated wire mesh platform to allow access to the ventral surface of the hind paws. A steel rod (diameter $0.5 \mathrm{~mm}$ ) was pushed against the hind paw with ascending force (touch stimulator). The force ranged from 0 to $35 \mathrm{~g}$ over a $20 \mathrm{~s}$ period. When the animal withdrew the hind paw, the mechanical stimulus was automatically stopped, and the force applied in the animal to withdraw the paw was recorded to the nearest $0.1 \mathrm{~g}$. The paw withdrawal threshold was measured after 4 consecutive stimuli into the injected paw. The measurements were made on day 0 (baseline before CFA-injection), and days 7, 10, 14, and 21 after CFA-injection. Results were analyzed comparing treated groups with negative control (saline).

All treated groups were compared with the control group and the results were analyzed statistically using one-way analysis of variance (ANOVA), followed by Duncan's test to identify the differences between treated groups and control. The data were considered significant at $p \leq 0.05$ level.

\section{Results}

The results on the open-field test demonstrated that oral (p.o.) treatment with both dichloromethane P. pubescens fruit extract $(\mathrm{Pp})$ and aqueous $P$. pubescens fruit extract (Ppa) in a dose-dependent manner based on logarithmic scale (30, 
100 and $300 \mathrm{mg} \mathrm{kg}^{-1}$ ) did not cause any significant changes in the ambulatory behavior of mice (not shown). However, the intraperitoneal (i.p.) treatment with the positive control pentobarbital ( $\left.35 \mathrm{mg} \mathrm{kg}^{-1}\right)$ significantly $(p \leq 0.001)$ reduced the locomotor activity of animals on this assay, compared to the group that received vehicle. These data validated the dose-response curves designed for this study, especially for the behavioral methods used for samples antinociceptive activity evaluation, avoiding results misinterpretation.

The dose-response curves observed in Figure 1, show the effectiveness of dichloromethane $P$. pubescens fruit extract (Pp) and aqueous $P$. pubescens fruit extract (Ppa) extracts on reducing the number of abdominal constrictions compared to control group (vehicle only, p.o.). Groups treated with 10, 30, and $100 \mathrm{mg} \mathrm{kg}^{-1}$ doses of Ppa extract (absence of geranylgeraniol), were effective in reducing writhing by $17, * 54$, and $* 49 \%$, respectively, presenting $\mathrm{ED}_{50}(50 \%$ effective dose $)=33.5 \mathrm{mg} \mathrm{kg}^{-1}(* p \leq 0.05)$. Whereas, groups treated with 10 , 30, and $100 \mathrm{mg} \mathrm{kg}^{-1}$ doses of Pp extract (presence of geranylgeraniol) decreased writhing by $* 54, * 49$, and $* * 73 \%$, respectively, presenting $\mathrm{ED}_{50}=22.2 \mathrm{mg} \mathrm{kg}^{-1}(* p \leq 0.05 ; * * p \leq 0.01)$. For these comparisons, a positive control was not needed.

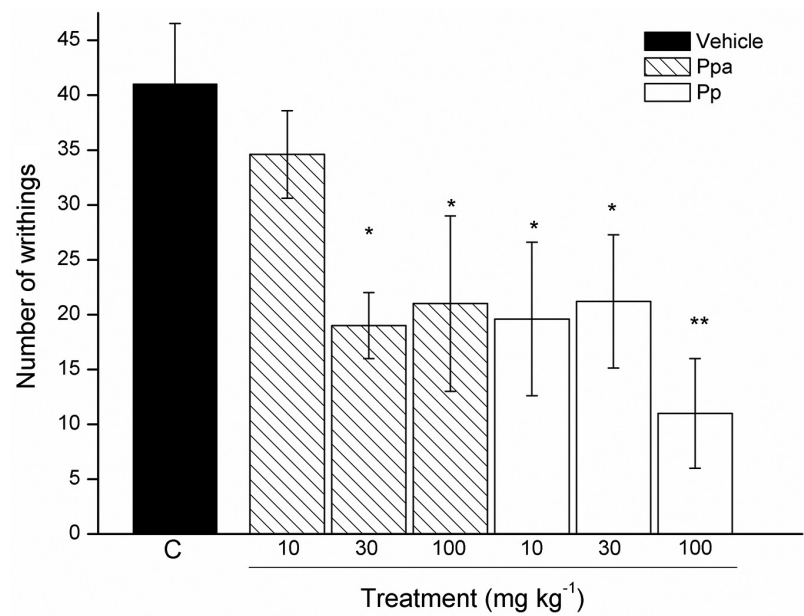

Figure 1. Abdominal constrictions induced by acetic acid ( $0.8 \%$ in saline) in mice previously treated $(60 \mathrm{~min})$ p.o. with control vehicle $\left(10 \mathrm{~mL} \mathrm{~kg}^{-1}\right)$, or Pp and Ppa extracts (10, 30, and $100 \mathrm{mg} \mathrm{kg}^{-1}$ doses; p.o.). Each column represents the mean \pm S.E.M. of up to 6 animals for experimental groups $(* p \leq 0.05, * * p \leq 0.01)$.

Results presented in Figure 2 demonstrated both phases of formalin test when animals were treated p.o. with Ppa extract, $60 \mathrm{~min}$ prior to formalin injection. Compared to control group (vehicle), in the first neurogenic phase (0-5 min) only the $300 \mathrm{mg} \mathrm{kg}^{-1}$ dose decreased significantly animals reaction time by $30 \%(* p \leq 0.05)$. In the second inflammatory phase (15-30 min), the extract demonstrated effectiveness under a dose-response manner, reducing reaction time by $* * 48 \%$ and $* * * 86 \%$, with 100 and $300 \mathrm{mg} \mathrm{kg}^{-1}$ doses, respectively, presenting $\mathrm{ED}_{50}=114.1 \mathrm{mg} \mathrm{kg}^{-1}(* * p \leq 0.01 ; * * * p \leq 0.001)$. Treatment evaluation with Pp extract in the same assay is demonstrated in Figure 3 where, in the first phase the extract was more effective than Ppa extract, decreasing the reaction time by $* 36,23$, and $* 58 \%$, under 30, 100, and $300 \mathrm{mg} \mathrm{kg}^{-1}$ doses, respectively ( $* p \leq 0.05$ ). Moreover, in the second phase $\mathrm{Pp}$ extract decreased the reaction time by $8, * * 50$, and $* * * 99 \%$, with 30,100 and $300 \mathrm{mg} \mathrm{kg}^{-1}$ doses, respectively, presenting $\mathrm{ED}_{50}=89.8 \mathrm{mg} \mathrm{kg}^{-1}$ (**p $\leq 0.01$; ***p $\leq 0.001$ ).

The anti-inflammatory properties of both extracts are shown in Figure 4. Higher effectiveness of Pp compared to

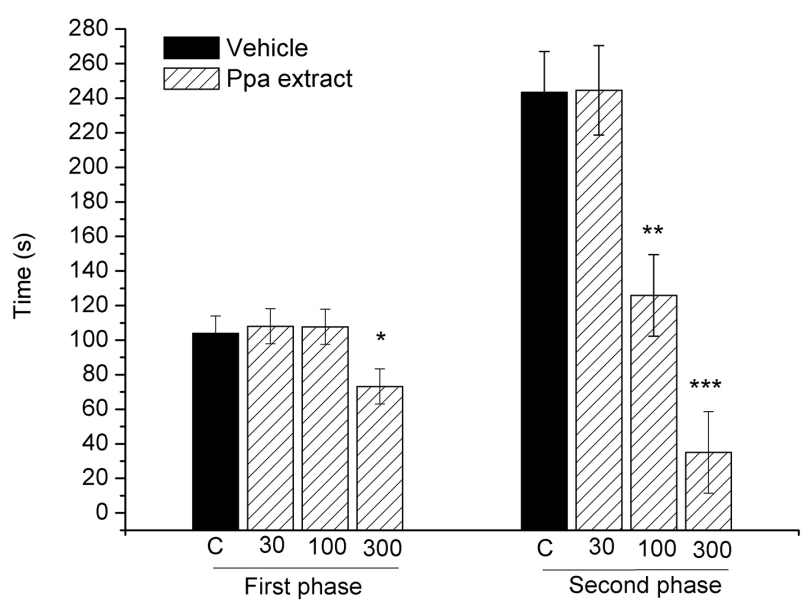

Figure 2. Graph demonstrating Ppa extract effects on licking induced by formalin in mice. Animals were treated with vehicle, Ppa (30, 100 and $300 \mathrm{mg} \mathrm{kg}^{-1}$ doses; p.o.) prior to formalin. The total time spent licking the hind paw was measured in the first and second phase after intraplantar injection of formalin. Each column represents the mean \pm S.E.M. of up to 6 mice in each group $\left(* p \leq 0.05, * * p \leq 0.01\right.$, $\left.{ }^{* * *} p \leq 0.001\right)$.

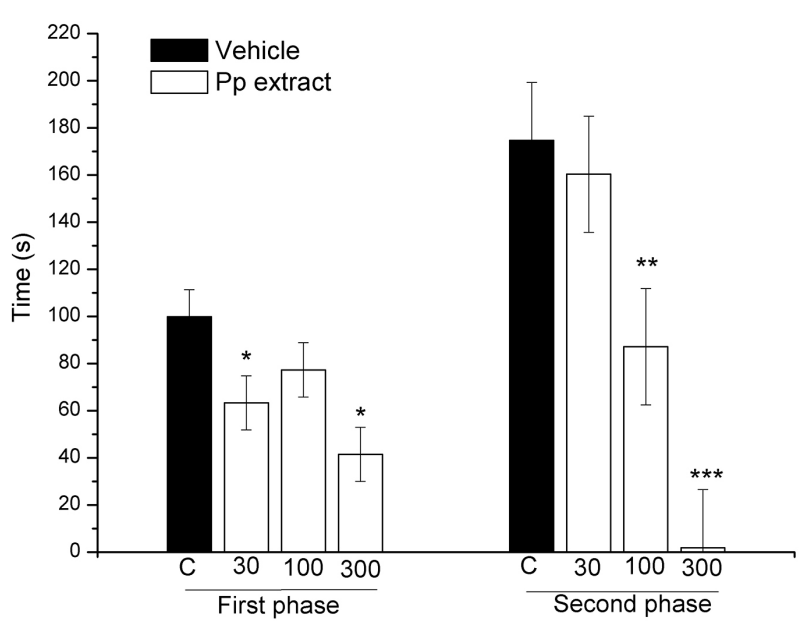

Figure 3. Graph demonstrating Pp extract effects on licking induced by formalin in mice. Animals were treated with vehicle, $P p(30,100$ and $300 \mathrm{mg} \mathrm{kg}^{-1}$ doses; p.o.) prior to formalin. The total time spent licking the hindpaw was measured in the first and second phase after intraplantar injection of formalin. Each column represents the mean \pm S.E.M. of up to 6 mice in each group $(* p \leq 0.05, * * p \leq 0.01, * * * p \leq 0.001)$. 
Ppa extract on reducing paw edema in the acute phase of the experiment was observed, compared to the control group (vehicle). The p.o. treatment with $300 \mathrm{mg} \mathrm{kg}^{-1}$ of Ppa extract (Figure $4 \mathrm{~A}$ ), decreased significantly paw edema by $* 35$ and $* 49 \%, 4$ and $6 \mathrm{~h}$ after carrageenan injection respectively $(* p \leq 0.05)$. Whereas, p.o. treatment with 30,100 , and $300 \mathrm{mg} \mathrm{kg}^{-1}$ of Pp extract (Figure 4B) significantly reduced paw edema $4 \mathrm{~h}(* * 48, * * 39$, and $* * 40 \%$, respectively) and $6 \mathrm{~h}(* * 39, * * 40$, and $* * 58 \%$, respectively) post carrageenan injection $(* * p \leq 0.01)$.

The results presented in Figure 5 show that p.o. treatment 60 min beforehand with both $\mathrm{Ppa}(\mathrm{A})$ and $\mathrm{Pp}(\mathrm{B})$ extracts produced significant anti-hyper nociceptive effects, increasing the percentage of stimulus compared to the control group (only vehicle $10 \mathrm{mg} \mathrm{kg}^{-1}$ ). All doses tested $\left(30,100\right.$, and $\left.300 \mathrm{mg} \mathrm{kg}^{-1}\right)$ were effective in this assay $\left({ }^{*} p \leq 0.05 ; * * p \leq 0.01\right)$.

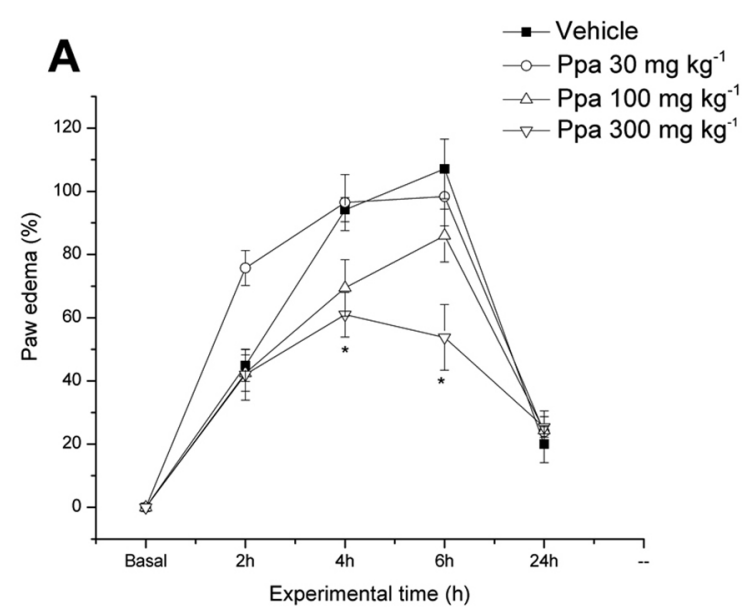

The results shown in Figures 6 and 7 demonstrate two different parameters analyzed in the same assay, in order to measure and compare the activity of the p.o. treatments with Ppa and Pp extracts in the CFAinduced arthritis model: the arthritis index (paw joint edema) and mechanical allodynia (pain perception). The daily treatment with positive control dexamethasone (10 $\mathrm{mg} \mathrm{kg}^{-1}$, p.o.) significantly reduced arthritis index by $* * * 74$ and $* * * 63 \%, 14$ and 21 days after CFA injection. Graph presented in Figure 6A indicates that the daily treatment with Ppa (30, 100 and $300 \mathrm{mg} \mathrm{kg}^{-1}$ doses, p.o.) starting 7 days after CFA injection, reduced arthritis index by 30,21 , and $26 \%$, respectively. These reductions were not significantly different from the negative control group (vehicle, $10 \mathrm{~mL} \mathrm{~kg}^{-1}$ ). Results in Figure 6B show that daily treatment with Pp extract (30, 100 and $300 \mathrm{mg} \mathrm{kg}^{-1}$ doses, p.o.) starting 7 days after CFA injection, significantly

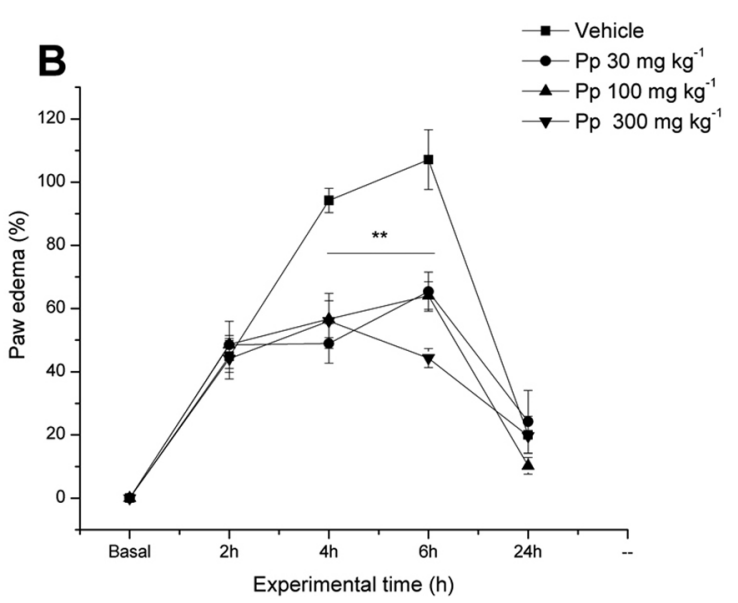

Figure 4. Effects of the p.o. treatment 60 min beforehand with Ppa (A) and Pp (B) extracts on the carrageenan-induced paw edema in mice. Results expressed as increased percentage in paw edema compared to the baseline volume, after inflammation induction. Each point represents the mean \pm S.E.M. of up to 6 animals. The significance levels $\left(* p \leq 0.05\right.$ and ${ }^{* *} p \leq 0.01$ ) were compared with control groups (only vehicle, $10 \mathrm{~mL} \mathrm{~kg}^{-1}$ ).
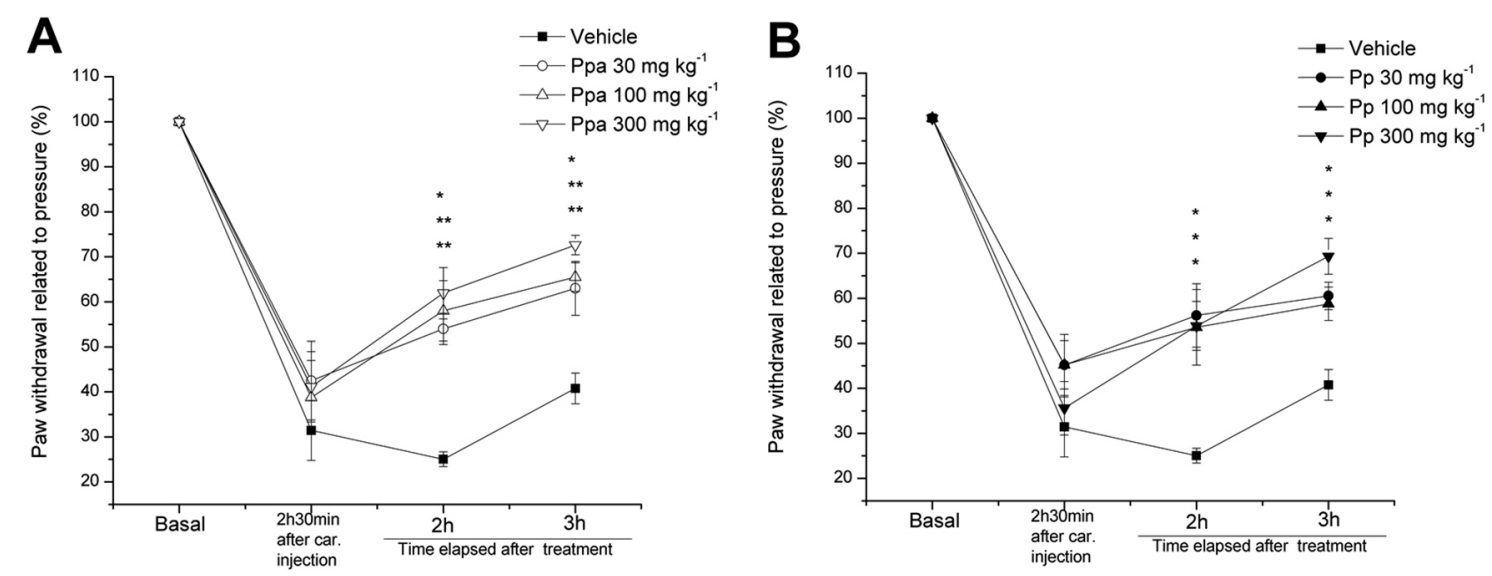

Figure 5. Graphs demonstrating results of vocalization or paw withdrawal related to pressure exerted in the right hind paw in response to the hypernociception caused by injection of carrageenan $(2.5 \%, 0.1 \mathrm{~mL})$ in rats p.o. treated with Ppa (A) and Pp (B) 30, 100 and $300 \mathrm{mg} \mathrm{kg}^{-1}$ doses compared to the control group (vehicle). Results expressed as reduction percentage means \pm S.E.M. of up to 6 animals for experimental groups compared to the basal values (considered $100 \%)(* p \leq 0.05, * * p \leq 0.01)$. 

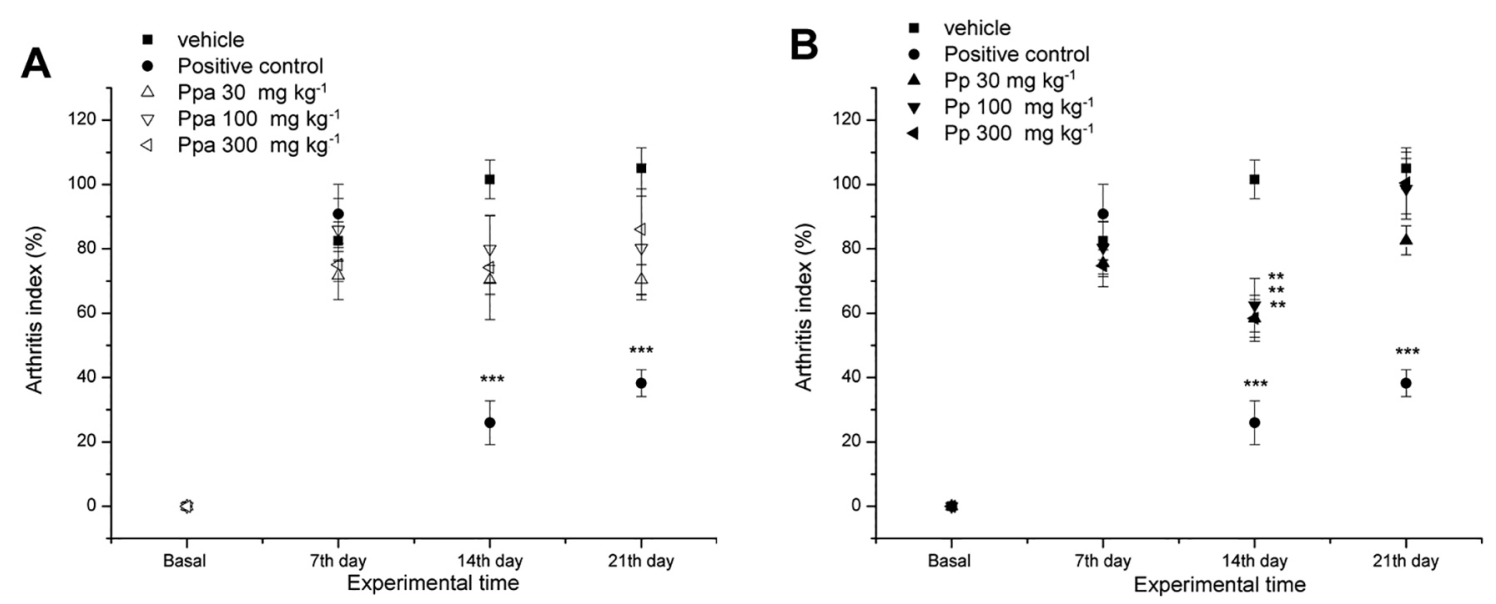

Figure 6. Effects of the daily treatments with vehicle $\left(10 \mathrm{~mL} \mathrm{~kg}^{-1}\right)$, positive control dexamethasone $\left(10 \mathrm{mg} \mathrm{kg}^{-1}\right)$, Pp, and Ppa extracts (30, 100 , and $300 \mathrm{mg} \mathrm{kg}^{-1}$ ) on the CFA-induced arthritis model in rats. Results expressed as arthritis index percentage decreased, compared to the negative control group vehicle. Each point represents the mean \pm S.E.M. of up to 6 animals $(* * p \leq 0.01$ and $* * * p \leq 0.001)$.

reduced arthritis index on the $14^{\text {th }}$ experimental day by $* * 42, * * 38$, and $* * 42 \%$, respectively $(* * p \leq 0.01)$.

The mechanical allodynia assessments started on day 10 after CFA injection. Measurements for positive control dexamethasone $\left(10 \mathrm{mg} \mathrm{kg}^{-1}\right)$ showed significant activity in all time points tested $(* * * p \leq 0.001)$. The results in Figure 7A demonstrate that daily p.o. treatment with Ppa (30, 100, and $300 \mathrm{mg} \mathrm{kg}^{-1}$ doses) were significantly active after $14^{\text {th }}$ day with 100 and $300 \mathrm{mg} \mathrm{kg}^{-1}$ doses increasing withdrawal threshold by $* * * 87$ and $* * * 86 \%$, respectively. On $21^{\text {st }}$ day, $300 \mathrm{mg} \mathrm{kg}^{-1}$ dose also increased withdrawal threshold significantly $(* * * p \leq 0.001)$. Figure 7B demonstrates that the daily administration of Pp (30, 100 and $300 \mathrm{mg} \mathrm{kg}^{-1}$ doses, p.o.) starting after 7 days of CFA-injection, increased the withdrawal threshold pressure since the $10^{\text {th }}$ experimental day, by $* * * 67, * * * 87$, and $* * * 90 \%$, respectively. The significant effectiveness continued until the end of the experiment ( $21^{\text {st }}$ day) with 100 and $300 \mathrm{mg} \mathrm{kg}^{-1}$ doses.

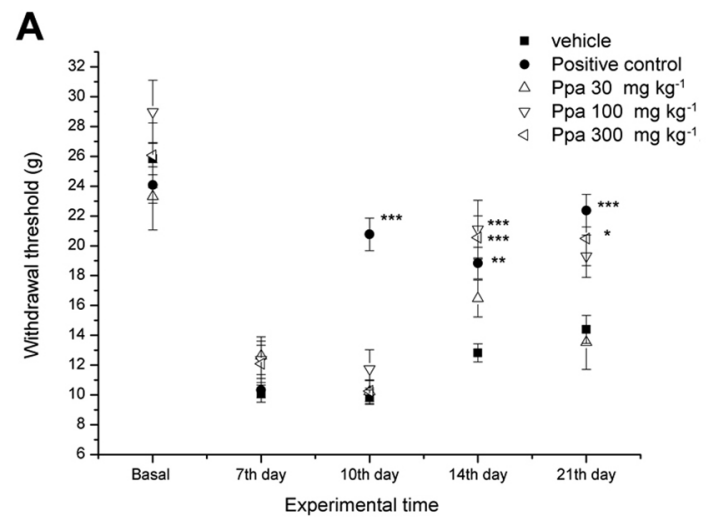

\section{Discussion}

We previously reported antinociceptive properties of diterpenes isolated from the P. pubescens fruit, demonstrating that the main compounds related to the biological activities were cyclic diterpenes: $6 \alpha, 7 \beta$ dihydroxyvouacapan-17$\beta$-oate methyl ester, and isomers $6 \alpha$-hydroxy-7 $\beta$-acetoxy-vouacapan-17 $\beta$-oate methyl ester and $6 \alpha$-acetoxy-7 $\beta$-hydroxy-vouacapan-17 $\beta$-oate methyl ester, and acyclic isoprenoid geranylgeraniol. These compounds demonstrated to play an important role in antinociceptive and anti-inflammatory properties attributed to $P$. pubescens fruit crude extract, possibly by synergism. ${ }^{8,23,24}$ In fact, the absence of geranylgeraniol in the composition of the crude aqueous $P$. pubescens fruit extract (Ppa) containing the same amount of the main cyclic diterpenes produced less antinociceptive activity in as the experimental animal models evaluated (Figure 9). Therefore, the most relevant findings of the present work

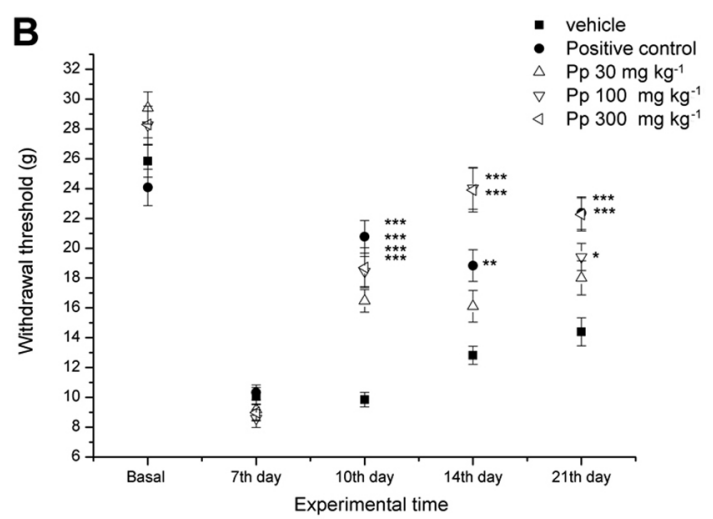

Figure 7. Effects of daily treatments with vehicle $\left(10 \mathrm{~mL} \mathrm{~kg}^{-1}\right)$, positive control dexamethasone $\left(10 \mathrm{mg} \mathrm{kg}^{-1}\right)$, Pp, and Ppa extracts $\left(30,100\right.$, and $300 \mathrm{mg} \mathrm{kg}{ }^{-1}$ doses) on CFA-induced arthritis rat model. Results expressed as mechanical allodynia pressure (withdrawal threshold in grams), compared to the negative control group vehicle. Each point represents the mean \pm S.E.M. of up to 6 animals $\left({ }^{*} p \leq 0.05 ; * * p \leq 0.01\right.$; and $\left.* * * p \leq 0.001\right)$. 
<smiles>CC1CCCC23Cc4ccoc4C(C)C2C=CCC13</smiles>

1
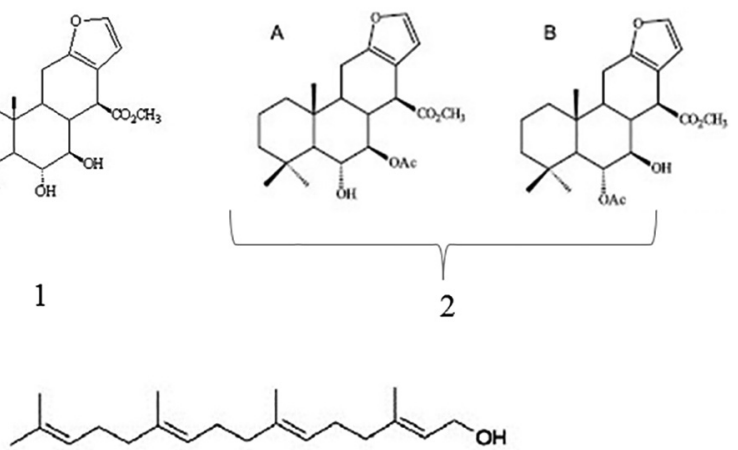

3
Figure 8. Chemical structure of (1) $6 \alpha, 7 \beta$-dihydroxyvouacapan-17 $\beta$-oate methyl ester, (2) isomers $6 \alpha$-hydroxy-7 $\beta$-acetoxy-vouacapan-17 $\beta$-oate methyl ester and $6 \alpha$-acetoxy-7 $\beta$-hydroxy-vouacapan-17 $\beta$-oate methyl ester, and (3) acyclic isoprenoid geranylgeraniol.

were that: $(i)$ chemically, the extracts showed important differences in chemical profile, the lack of geranylgeraniol in the aqueous $P$. pubescens fruit crude extract (Ppa) decreased the antinociceptive activity; (ii) the number of chemical-induced models performed were sufficient to determine differences in extracts efficiency against pain and inflammation; (iii) compared to the aqueous $P$. pubescens fruit crude extract (Ppa), the dichloromethane $P$. pubescens fruit crude extract $(\mathrm{Pp})$ demonstrated a greater effectiveness in writhing-, formalin-, carrageenan-tests, and CFA-induced arthritis models; (iv) both extracts demonstrated the same statistical effectiveness against carrageenan-induced hyper nociception in rats; $(v)$ the absence of geranylgeraniol in the aqueous $P$. pubescens fruit crude extract might explain the significant differences on the pharmacologic properties between Pp and Ppa extracts obtained from P. pubescens.

This work was conducted with classical animal models routinely performed in our laboratory, which can provide useful and essential systems designed for the evaluation of the basic properties against pain and inflammation. ${ }^{8,23,28}$ We first evaluated whether both extracts could interfere in the ambulatory animals behavior, in order to exclude the possibility that their antinociceptive properties could have relationship with non-specific disturbances in the locomotor activity, avoiding misinterpretation of results. These alterations might be resulted from either brain activation, manifested as excitation/depression of central neurons, or a relaxant activity at the neuromuscular junction level. ${ }^{32}$ The results in the open-field test validated the antinociceptive results observed in the dose-response curves designed for this study, considering that even the highest dosage tested did not interfere in the ambulatory animals' behavior.

The acetic acid-induced abdominal constriction is a standard, simple, and sensitive test for measuring both central and peripheral induced analgesia. This test is commonly employed as a visceral inflammatory pain model ${ }^{33}$ In acetic acid-induced abdominal constriction, pain is elicited by injection of an irritant such as acetic acid into the peritoneal cavity which produces episodes of characteristic stretching (writhing) movements and inhibition of number of episodes by analgesics is easily quantified. ${ }^{34}$ This is a convenient stimulus assay for screening, since the intensity of response depends on the interaction of several factors, neurotransmitters and

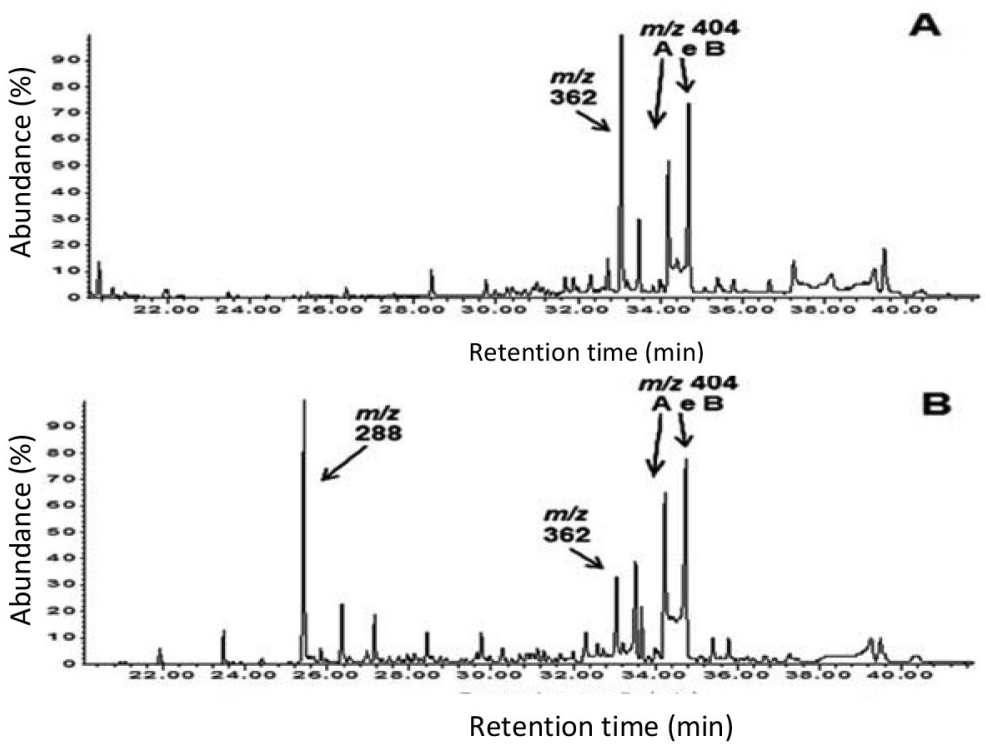

Figure 9. GC-MS (HP6890/HP5975) normalized chromatograms of aqueous (A) and dichloromethane (B) extract. Compounds highlighted are geranylgeraniol

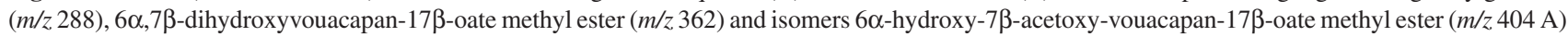

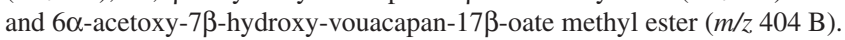


neuromodulators that determine nociception (kinines, acetylcholine, $\mathrm{P}$ substance and prostaglandins). The acid acts indirectly by inducing mediator release, which stimulate the nociceptive neurons. Therefore this model is sensitive to drugs with analgesic activity possessing the most varied mechanisms of action, permitting antinociceptive activity evaluation caused by both neurogenic and/or inflammatory pain stimuli. ${ }^{35}$ On this experimental model, the oral treatment showed that Pp extract $\left(\mathrm{ED}_{50} 22.5 \mathrm{mg} \mathrm{kg}^{-1}\right)$ was $32 \%$ more effective than Ppa extract $\left(\mathrm{ED}_{50} 33.5 \mathrm{mg} \mathrm{kg}^{-1}\right)$, and these differences have probably relationship with geranylgeraniol in $\mathrm{Pp}$ extract, corroborating our previous results which demonstrated the higher potency of geranylgeraniol given orally $\left(\mathrm{ED}_{50} 26.7 \mathrm{mg} \mathrm{kg}^{-1}\right)$, compared with the cyclic diterpenes $6 \alpha, 7 \beta$-dihydroxyvouacapan$17 \beta$-oate methyl ester $\left(\mathrm{ED}_{50} 35.6 \mathrm{mg} \mathrm{kg}^{-1}\right)$, and isomers $6 \alpha$-hydroxy-7 $\beta$-acetoxy-vouacapan-17 $\beta$-oate methyl ester and $6 \alpha$-acetoxy-7 $\beta$-hydroxy-vouacapan-17 $\beta$-oate methyl ester $\left(\mathrm{ED}_{50} 35.6 \mathrm{mg} \mathrm{kg}^{-1}\right)$, in the same assay and route of administration. ${ }^{8,24}$ We also suggest that geranylgeraniol might increase $\mathrm{Pp}$ extract activity by acting peripherally via serotonergic and/or imidazoline systems, as described previously. ${ }^{23}$

The vanilloid family receptors, such as TRPV ${ }_{1}$, respond to protons that are found in a low-pH environment (chemical-induced pain), which can be caused by inflammation of surrounding tissues ${ }^{36}$ therefore we further compared both Pp and Ppa extracts in formalin pain model, important to distinguish whether the extracts were able to decrease neurogenic (phase I) or inflammatory (phase II) pain stimuli. Neurogenic pain is caused by direct activation of nociceptive nerve terminals, whereas inflammatory pain is mediated by a combination of peripheral input and spinal cord sensitization. Formalin produces significant increase in spinal levels of different mediators related to both neurogenic (amino acids, kinins) and inflammatory pathways (prostaglandins, leukotrienes, cytokines). The tonic inflammatory pain induced by formalin, produced a distinct biphasic paw-flinching response that can be divided into phase I (0-10 min) and phase II (within 40-60 min). ${ }^{37}$ The oral treatment with Pp and Ppa extracts significantly inhibited both the early and late phases of this test, demonstrating significant differences in effectiveness outcome. Pp extract was effective in the first phase, which is mediated by the direct chemical nociceptors activation. Whereas, Ppa extract did not show a significant activity in this phase, demonstrating the essential role of geranylgeraniol in the reduction of neurogenic pain stimuli induced by chemicals such as formalin. On the late phase II, both extracts demonstrated similar activity, suggesting that on the inflammatory response, the absence of geranylgeraniol did not interfere as much as expected. Thereupon we also explored how effective Pp and Ppa extracts could be in the inflammatory process caused by carrageenan injection, inducing edema and hyperalgesia in mice paw.

Inflammation is a multicellular process in which various types of cells, molecules, messengers, and plasma proteins participate in a highly effective and organized manner. ${ }^{38}$ Inflammatory response occurs in three distinct temporal phases, each mediated by different mechanisms: an acute phase characterized by transient vasodilatation and increased capillary permeability; a delayed sub-acute phase characterized by infiltration of leukocytes and phagocytic cells; a chronic proliferative phase in which tissue degeneration and fibrosis occur. ${ }^{39}$ Many mechanisms are involved in the promotion and resolution of the inflammatory process and hyperalgesia. ${ }^{40,41}$ Persistent and recurrent episodes of chronic inflammation mediated by activation of innate and acquired immunity is characteristic of a wide spectrum of idiopathic and infectious chronic inflammatory disorders. ${ }^{42}$ Some authors ${ }^{21}$ demonstrated that $P$. pubescens' ethanol extract, during an inflammatory episode, was able to suppress both cellular and humoral immune responses in lower concentrations compared to dexamethasone (immunosuppressant drug). The description of the influence of lupeol and botulin in the anti-inflammatory properties of ethanol extract were also reported. ${ }^{43}$ Our results demonstrated the influence of geranylgeraniol in the intensity of anti-inflammatory activity under edematogenic mechanisms. The early phase starts immediately after carrageenan injection and lasts for approximately $6 \mathrm{~h}$, also leads to activation and secretion of mediators that include bradykinin and arachidonic acid metabolites such as prostaglandins and leukotrienes. ${ }^{44}$ The participation of geranylgeraniol was represented by higher effectiveness of Pp extract on reducing paw edema in the acute phase of inflammatory process, compared to aqueous extract Ppa. These results motivated us to further explore whether both extracts could reduce hyperalgesia caused by carrageenan, in order to observe the potential of compounds to reduce not only edematogenic agents, but also pain associated with this process. Therefore, anti-hyper nociceptive effects of both extracts were evaluated in carrageenan-induced hyperalgesia, a model widely used for studying inflammation. ${ }^{39,45}$ In this model, carrageenan evokes a very inflammatory and nociceptive response characteristic, which is mediated by different groups of endogenous substances that stimulate chemo sensitive nociceptors, thus playing a major role in the development of inflammatory pain. Such process produces central sensitization in response to release 
of pro-inflammatory mediators, which increase the sensitivity of peripheral and central sensory pathways. ${ }^{44}$ These results corroborated late phase data in formalin test, with both extracts demonstrating similar activity on decreasing the inflammatory pain stimulus. Moreover, we also evaluated whether Pp and Ppa extracts could be active under an arthritis model in rats, based on the Pterodon pubescens' folk medicine infusion commonly used for rheumatoid arthritis in humans, nevertheless with no scientific evidences for this ethno pharmacological knowledge. Rheumatoid arthritis (RA) is characterized by inflammatory cell infiltration and proliferation of synovial tissue, accompanied by bone destruction, and can quickly progress into multi system inflammation with irreversible joint damage causing premature mortality, disability, and compromised life quality. ${ }^{46,47}$ Pain, stiffness, swelling, deformity, and eventually joints function loss are common manifestations in RA. ${ }^{48}$ The disease is usually treated with anti-inflammatory and immunosuppressive drugs which cause important side effects, therefore new strategies for arthritis treatment are required. Medicinal plants are an important source of new leads for this purpose. ${ }^{49}$ Sabino et al..$^{50}$ reported treatment of collagen-induced arthritis in mice with $P$. pubescens' seeds hydroalcoholic extract. CFA-induced arthritis in rats is a widely used experimental animal model of inflammatory polyarthritis characterized by infiltration of synovial membrane and associated with joints destruction, which resembles closely to those clinical and pathological features of human RA. ${ }^{50,51}$ Rats with adjuvant-induced arthritis (AA) are widely accepted as an appropriate model for screening potential anti-RA drugs. ${ }^{52}$ Our study demonstrated that Ppa extract which was deprived of geranylgeraniol content was effective in the measurement of mechanical allodynia, but not in paw swelling caused by CFA-injection. Whereas, Pp extract containing geranylgeraniol, demonstrated effectiveness in both evaluations decreasing mechanical allodynia and paw swelling compared to their control groups, in a dose-dependent manner.

\section{Conclusions}

Overall results presented herein corroborate traditional use of this species. Moreover our data highlighted the importance of geranylgeraniol to improve $P$. pubescens fruit extracts outcome against inflammatory pain. Further studies evaluating the potential of these extracts against neuropathic pain are in course. These data are in accordance with the hypothesis stating the potential use of these extracts in the treatment of chronic pain.

\section{Acknowledgments}

The authors are thankful to FCF/UNICAMP, Fundação de Amparo à Pesquisa do Estado de São Paulo (FAPESP), Conselho Nacional para o Desenvolvimento Científico e Tecnológico (CNPq), and Coordenação de Aperfeiçoamento de Pessoal de Nível Superior (CAPES) for financial support.

\section{References}

1. Mili, F.; Helmick, C. G.; Zack, M. M.; J. Rheumatol. 2002, 29 , 1981.

2. Schaible, H. G.; Ebersberger, A. V.; Banchet, G. S.; Ann. N. Y. Acad. Sci. 2002, 966, 343.

3. Scholz, J.; Woolf, C. J.; Nat. Neurosci. 2002, 5, 1062.

4. Silman, A. J.; Pearson, J. E.; Arthritis Res. Ther. 2002, 4, S265.

5. Melton, L.; Lancet Neurol. 2003, 2, 524.

6. Wang, L.; Wang, Z.; Adv. Drug Delivery Res. 2003, 55, 949.

7. Coelho, L. P.; Reis, P. A.; Castro, F. L.; Gayer, C. R. M.; Lopes, C. S.; Silva, M. C. C.; Sabino, K. C. C.; Todeschini, A. R.; Coelho, M. G. P.; J. Ethnopharmacol. 2005, 98, 109.

8. Spindola, H. M.; Servat, L.; Denny, C.; Rodrigues, R. A. F.; Eberlin, M. N.; Cabral, E.; Sousa, I. M. O.; Tamashiro, J. Y.; Carvalho, J. E.; Foglio, M. A.; BMC Pharmacol. 2010, 10, 1.

9. Mors, W. B.; Santos, M. F.; Monteiro, H. B.; Science 1967, 157, 950.

10. dos Santos Filho, D.; Sarti, S. J.; Katz, N.; Araújo, N.; Rocha Filho, P. A.; Abreu, J. E.; Bortolin, M. E.; Mem. Inst. Oswaldo Cruz 1987, 82, 343.

11. Nunan, E. A.; Carvalho, M. G.; Piloveloso, D.; Braz. J. Med. Biol. Res. 1982, 15, 450.

12. Katz, S.; Branch, L. G.; Branson, M. H.; Papsidero, J. A.; Beck, J. C.; Greer, D. S.; N. Engl. J. Med. 1983, 20, 1218.

13. Duarte, I. D. G.; Alves, D. L. F.; Veloso, D. P.; Nakamura-Crag, M.; J. Ethnopharmacol. 1996, 55, 13.

14. Carvalho, J. C. T.; Sertie, J. A. A.; Barbosa, M. V. J.; Patricio, K. C. M.; J. Ethnopharmacol. 1999, 64, 127.

15. Arriaga, A. M. C.; Castro, M. A. B.; Silveira, E. R.; Braz-Filho, R.; J. Braz. Chem. Soc. 2000, 11, 187.

16. Coelho, M. G. P.; Marques, P. R.; Gayer, C. R. M.; Vaz, L. C. A.; Neto, J. F. N.; Sabino, K. C. C.; J. Ethnopharmacol. 2001, 77,159

17. Silva, M. C. C.; Gayer, C. R. M.; Lopes, C. S.; Calixto, N. O.; Reis, P. A.; Passeas, C. P. B.; Paes, M. C.; Dalmau, S. R.; Sabino, K. C. C.; Todeschini, A. R.; Coelho, M. G. P.; Pharm. Pharmacol. 2004, 56, 135.

18. Calixto, N. O.; da Costa e Silva, M. C.; Gayer, C. R.; Coelho, M. G.; Paes, M. C.; Todeschini, A. R.; Planta Med. 2007, 73, 480 . 
19. Vieira, C. R.; Marques, M. F.; Soares, P. R.; Matuda, L.; de Oliveira, C. M. A. P.; Kato, L.; da Silva, C. C.; Guillo, L. A.; Phytomedicine 2008, 15, 528.

20. Menna-Barreto, R. F. S.; Laranja, G. A. T.; Silva, M. C. C.; Coelho, M. G. P.; Paes, M. C.; Oliveira, M. M.; de Castro, S. L.; J. Parasitol. Res. 2008, 103, 111.

21. Cardoso, C. C.; Pinto, A. C.; Marques, P. R.; Gayer, C. R. M.; Afel, M. I. R.; Coelho, M. G. P.; Sabino, K. C. C.; Pak. J. Biol. Sci. 2008, 11, 2308.

22. Spindola, H. M.; Carvalho, J. E.; Ruiz, A. L. T. G.; Rodrigues, R. A. F.; Denny, C.; Sousa, I. M. O.; Tamashiro, J. Y.; Foglio, M. A.; J. Braz. Chem. Soc. 2009, 20, 569.

23. Spindola, H. M.; Servat, L.; Carvalho, J. E.; Rodrigues, R. A. F.; Sousa, I. M. O.; Foglio, M. A.; Eur. J. Pharm. 2011, 656, 45.

24. Servat, L.; Spindola, H. M.; Rodrigues, R. A. F.; Sousa, I. M. O.; Ruiz, A. L. T. G.; Carvalho, J. E.; Foglio, M. A.; J. Braz. Chem. Soc. 2012, 23, 1244.

25. Cabral, E. C.; Servatt, L.; Spindola, H. M.; Coelho, M. B.; Sousa, I. M. O.; Queiroz, N. C. A.; Foglio, M. A.; Phytochem. Anal. 2013, 24, 184.

26. Voipio, H. M.; Baneux, P.; Gomez de Segura, I. A.; Hau, J.; Wolfensohn, S.; Lab. Anim. 2008, 42, 1.

27. Koster, R.; Anderson, M.; De Beer, E. J.; Fed. Proc. 1959, 18 , 412.

28. Spindola, H. M.; Vendramini-Costa, D. B.; Rodrigues Jr., M. T.; Foglio, M. A.; Pilli, R. A; Carvalho, J. E.; Pharmacol., Biol. Behav. 2012, 102, 133.

29. Dubuisson, D.; Dennis, S. G.; Pain 1977, 4, 161.

30. Winter, C. A.; Risley, E. A.; Nuss, G. W.; Proc. Soc. Exp. Biol. Med. 1962, 111, 544.

31. Omura, K.; Imai, S.; Maeda, T.; Hukuda, S.; J. Rheumatol. 1998, 25, 936.

32. Calabresi, P.; Centonze, D.; Gubellini, P.; Pisani, A.; Bernardi, G.; Trends Neurosci. 2000, 23, 120.

33. Hunskaar, S.; Pharm. Toxicol. 1987, 60, 167.

34. Shafiee, A.; Bagheri, M.; Shekarchi, M.; Abdollahi, M.; J. Pharmacol. Sci. 2003, 6, 360.

35. Collier, H. O.; Dinneen, L. C.; Johnson, C. A.; Schneider, C.; Br. J. Pharmacol. Chemother. 1968, 32, 295.
36. Caterina, M. J.; Schumacher, M. A.; Tominaga, M.; Rosen, T. A.; Levine, J. D.; Julius, D.; Nature 1997, 23, 816.

37. Wang, Z.; Gardell, L. R.; Ossipov, M. H.; Vanderah, T. W.; Brennan, M. B.; Hochgeschwender, U.; Hruby, V. J.; Malan Jr., T. P.; Lai, J.; Porreca F.; J. Neurosci. 2001, 21, 1779.

38. Chopade, A. R.; Awale, S. S.; Naikwade, N. S.; J. Pharmacol. Res. 2009, 2, 541.

39. Basbaum, A. I.; Reg. Anesth. Pain Med. 1999, 24, 59.

40. Serhan, C. N.; Chiang, N.; Rheuma. Dis. Clin. North Am. 2004, $30,69$.

41. Chopade, A. R.; Pol, R. P.; Awale, S. S.; Naikwade, N. S.; Curr. Pharm. Res. J. 2006, 1, 87.

42. McCulloch, C. A.; Downey, G. P.; El-Gabalawy, H.; Nat. Rev. Drug Discovery 2006, 5, 864.

43. de Moraes, W. F.; Galdino, P. M.; Nascimento, M. V.; Vanderlinde, F. A.; Bara, M. T.; Costa, E. A.; de Paula, J. R.; J. Nat. Med. 2012, 66, 202.

44. Posadas, I.; Bucci, M.; Roviezzo, F.; Rossi, A.; Parente, L.; Sautebin, L.; Cirino, G.; Br. J. Pharmacol. 2004, 142, 331.

45. Minami, M.; Katayama, T.; Satoh, M.; J. Pharmacol. Sci. 2006, $100,461$.

46. Imboden, J. B.; Annu. Rev. Pathol.: Mech. Dis. 2009, 4, 417.

47. Brooks, P. M.; Clin. Rheumatol. 2006, 25, 778.

48. Soeken, K.; Miller, S.; Ernst, E.; Rheumatology 2003, 42, 652.

49. Hart, B. A.; Otten, H. G.; Pharm. World Sci. 1995, 17, 178.

50. Sabino, K. C. C.; Castro, F. A.; Oliveira, J. C. R.; Dalmau, S. R. A.; Coelho, M. G. P.; Phytother. Res. 1999, 13, 613.

51. Narendhirakannan, R.; Limmy, T.; Immunopharmacol. Immunotoxicol. 2012, 34, 326.

52. Greish, S.; Abogresha, N.; Abdel-Hady, Z.; Zakaria, E.; Ghaly, M.; Hefny, M.; World J. Stem Cells 2012, 4, 101.

Submitted: June 14, 2016

Published online: October 21, 2016

FAPESP has sponsored the publication of this article. 